\title{
Awake Prone Positioning in Non-Intubated Patients With Acute Hypoxemic Respiratory Failure Due to COVID-19
}

\author{
Ivan Pavlov, Hangyong He, Bairbre McNicholas, Yonatan Perez, Elsa Tavernier, \\ Matthew W Trump, Julie A Jackson, Wei Zhang, Daniel S Rubin, Thomas Spiegel, \\ Anthony Hung, Miguel Ángel Ibarra Estrada, Oriol Roca, David L Vines, David Cosgrave, \\ Sara Mirza, John G Laffey, Todd W Rice, Stephan Ehrmann, and Jie Li
}

\begin{abstract}
BACKGROUND: Awake prone positioning (APP) has been advocated to improve oxygenation and prevent intubation of patients with acute hypoxemic respiratory failure due to coronavirus disease 2019 (COVID-19). This paper aims to synthesize the available evidence on the efficacy of APP. METHODS: We performed a systematic review of proportional outcomes from observational studies to compare intubation rate in patients treated with APP or with standard care. RESULTS: A total of 46 published and 4 unpublished observational studies that included 2,994 subjects were included, of which 921 were managed with APP and 870 were managed with usual care. APP was associated with significant improvement of oxygenation parameters in 381 cases of 19 studies that reported this outcome. Among the 41 studies assessing intubation rates $(870$ subjects treated with APP and 852 subjects treated with usual care), the intubation rate was $27 \%$ (95\% CI 19-37\%) as compared to $30 \%(95 \%$ CI $20-42 \%)(P=.71)$, even when duration of application, use of adjunctive respiratory assist device (high-flow nasal cannula or noninvasive ventilation), and severity of oxygenation deficit were taken into account. There appeared to be a trend toward improved mortality when APP was compared with usual care $(11 \%$ vs $22 \%)$, which was not statistically significant. CONCLUSIONS: APP was associated with improvement of oxygenation but did not reduce the intubation rate in subjects with acute respiratory failure due to COVID-19. This finding is limited by the high heterogeneity and the observational nature of included studies. Randomized controlled clinical studies are needed to definitively assess whether APP could improve key outcome such as intubation rate and mortality in these patients. Key words: coronavirus disease 2019; severe acute respiratory syndrome coronavirus 2; ARDS; acute hypoxemic respiratory failure; high-flow nasal cannula; awake prone positioning; noninvasive ventilation; CPAP. [Respir Care 2022;67(1):102114. (C) 2022 Daedalus Enterprises]
\end{abstract}

\section{Introduction}

The coronavirus disease 2019 (COVID-19) pandemic has led to a sudden surge of hospital admissions for acute hypoxemic respiratory failure. A significant proportion of patients who are hospitalized for COVID-19 fulfills the criteria for the $\mathrm{ARDS}^{1}$ and requires prolonged mechanical ventilation. Prone positioning is one of the few interventions that has been proven to reduce mortality in intubated and mechanically ventilated patients with moderate to severe ARDS. ${ }^{2,3}$ This effect is likely mediated through a combination of better lung recruitment, reduced ventilation-perfusion mismatch, and prevention of alveolar strain and ventilator-induced lung injury by a more homogenous distribution of pleural pressures throughout the lung parenchyma. ${ }^{4}$

Groups worldwide have reported on the use of APP in acute hypoxemic respiratory failure due to COVID-19 and showed improvement of oxygenation and reduction of breathing frequency in populations with varying disease severity. ${ }^{5-11}$ Despite studies reporting outcomes being limited to case series and cohort studies, awake prone positioning (APP) has been widely adopted and included in the guidelines on management of COVID-19 pneumonia without any evidence that improvement of surrogate physiological 
end points translates into better clinical outcomes, such as reduced incidence of intubation or reduced mortality.

The aim of this systematic review of proportional outcomes from observational studies was to investigate the hypothesis that APP of non-intubated patients with acute hypoxemic respiratory failure due to COVID-19 results in reduced intubation rate. The impact of APP on intubation rate is the primary outcome, and its effects on oxygenation, mortality, and the tolerability of APP are reported as exploratory secondary outcomes. We also explored the impacts of the duration of APP; the severity of the acute hypoxemic respiratory failure; and the type of respiratory support, such as conventional oxygen therapy, high-flow nasal cannula (HFNC), or noninvasive ventilation (NIV), on respiratory parameters, intubation rate, and mortality.

Dr Pavlov is affiliated with the Department of Emergency Medicine, Hôpital de Verdun, Montréal, Québec, Canada. Dr He is affiliated with the Department of Respiratory and Critical Care Medicine, Beijing Institute of Respiratory Medicine, Beijing Chao-Yang Hospital, Capital Medical University, Beijing, China. Drs McNicholas, Cosgrave, and Laffey are affiliated with the Anaesthesia and Intensive Care Medicine, School of Medicine, National University of Ireland Galway and Department of Anaesthesia, University Hospital Galway, Saolta Hospital Group, Galway, Ireland. Drs Perez and Ehrmann is affiliated with Médecine Intensive Réanimation, CIC INSERM 1415, CRICSTriggerSEP research network, CHRU Tours, Tours, France and INSERM, Centre d'étude des pathologies respiratoires, U1100, Université de Tours, Tours, France. Dr Tavernier is affiliated with the INSERM 1246-SPHERE, Universities of Tours and Nantes, Tours, France; Clinical Investigation Center, INSERM 1415, CHRU Tours, Tours, France. Dr Trump is affiliated with the Department Pulmonary and Critical Care Medicine, The Iowa Clinic, West Des Moines, Iowa. Dr Jackson is affiliated with the Department of Respiratory Therapy, UnityPoint Health, Des Moines, Iowa. Dr Zhang is affiliated with the Department of Respiratory and Critical Care Medicine, First Affiliated Hospital, Second Military Medical University, Shanghai, China. Dr Rubin is affiliated with the Department of Anesthesia and Critical Care, University of Chicago, Chicago, Illinois. Dr Spiegel is affiliated with the Section of Emergency Medicine, Department of Medicine, University of Chicago, Chicago, Illinois. Dr Hung is affiliated with the Pritzker School of Medicine, University of Chicago, Chicago, Illinois. Dr Estrada is affiliated with the Intensive Care Unit, Hospital Civil Fray Antonio Alcalde, Universidad de Guadalajara. Guadalajara, Jalisco, Mexico. Dr Roca is affiliated with the Servei de Medicina Intensiva, Hospital Universitari Vall d'Hebron, Institut de Recerca Vall d'Hebron, Barcelona, Spain; Ciber Enfermedades Respiratorias (CIBERES), Instituto de Salud Carlos III, Madrid, Spain. Drs Vines and $\mathrm{Li}$ is affiliated with the Department of Cardiopulmonary Sciences, Division of Respiratory Care, Rush University Medical Center, Chicago, Illinois. Dr Mirza is affiliated with the Division of Pulmonary and Critical Care, Department of Internal Medicine, Rush University Medical Center, Chicago, Illinois. Dr Rice is affiliated with the Division of Allergy, Pulmonary, and Critical Care Medicine, Vanderbilt University School of Medicine, Nashville, Tennessee.

Dr Li discloses relationships with Fisher \& Paykel Healthcare, Aerogen, The Rice Foundation, and the American Association for Respiratory Care. She also serves as Section Editor for Respiratory Care. Drs Pavlov, Ehrmann, and Perez disclose relationships with Fisher \& Paykel

\section{Methods}

This study was registered on PROSPERO (CRD42020201947), and the detailed protocol is available (https://www.crd.york.ac.uk/prospero/display_record. php?RecordID=201947 Accessed September 28, 2021). Our findings are presented in conformity with the PRISMA guidelines. ${ }^{12}$

\section{Search Strategy and Study Selection}

Two investigators (HH and JL) searched the MEDLINE, Embase, PubMed, Web of Science, Scopus, medRixv, bioRixv, ClinicalTrials.gov, and Wanfang databases for studies published from January 1, 2020, to August 15, 2020, with restrictions to English and Chinese languages. The key words of "prone position*" OR "Pron*" AND "COVID-19" OR "SARS" OR "coronavirus" AND "awake" OR "non-intubated" OR "conscious" were utilized to search literature evaluating APP for subjects with COVID-19. This enabled the identification of cohorts of subjects treated with APP. The key words of "nasal highflow" OR "HFNC" OR "high-flow nasal cannula" OR "noninvasive ventilation" OR "NIV" OR "continuous positive airway pressure" OR "CPAP" AND "COVID-19" OR "SARS" OR "coronavirus" were used to identify reports of subjects treated with either HFNC or NIV/CPAP, without the use of APP, to be included as a control cohort. Equivalent key words were used for searches in Chinese. Searches were supplemented with examination of reference lists in identified studies and verbal communication with experts.

Healthcare. Dr Roca discloses relationships with Hamilton Medical and Air Liquide. Dr Laffey discloses a relationship with Baxter Healthcare; Dr Ehrmann discloses relationships with Fisher \& Paykel Healthcare, La Diffusion Technique Française, Aerogen, and Hamilton Medical. Ms Jackson and Dr Trump disclose relationships with Fisher \& Paykel Healthcare. Dr Rubin is the president of DRDR Mobile Health, a company that creates mobile applications for health care, including functional capacity assessment applications. Dr Vines discloses relationships with Ohio Medical, Theravance Biopharma, Teleflex Medical, and The Rice Foundation. The remaining authors disclose no conflicts of interest.

This work was supported by OpenAI and The Rice Foundation. The funding bodies had no role in the design of the study, in collection, analysis, and interpretation of data, nor in writing of the manuscript.

Drs Pavolv, He, McNicholas, and Perez are co-first authors.

Supplementary material related to this paper is available at http://www. rcjournal.com.

Correspondence: Jie Li PhD RRT RRT-ACCS RRT-NPS FAARC. Email: Jie_Li@rush.edu.

DOI: $10.4187 /$ respcare.09191 
Studies were included if they met the following criteria: (1) original research reports of COVID-19 subjects and (2) subjects were treated with APP and/or HFNC or NIV or conventional oxygen therapy. The exclusion criteria were (1) languages other than English or Chinese, (2) study protocols, review articles, abstracts, editorials, (3) research on newborns or animals, and (4) reports of fewer than 3 cases.

The investigators then independently parsed through the titles and abstracts of all identified articles and produced a list of potentially relevant papers. The full texts of these papers were then reviewed, and a final list of studies to be included in the meta-analysis was produced. Any disagreements were resolved by consensus.

Data from the articles were extracted by 2 independent teams (HH and JL, BM, and YP) using a standardized data extraction form. Extracted data included the authors, year of study, country, patient characteristics, the type of respiratory support, the details of APP intervention, tolerability, and outcomes. Any disagreements were resolved by consensus in the presence of all 4 investigators.

If the outcomes of intubation rate and mortality were not reported, or if it was not clear whether the subjects received APP and for what duration, the corresponding authors were contacted for clarifications. To enlarge the sample size, and to assess for the possibility of publication bias, unpublished data provided by the investigators' institutions (BM, JAJ, WZ, DSR) were also included in the meta-analysis. Ethical approval was obtained at each institution prior to data collection.

\section{Preplanned Statistical Analyses}

The primary outcome was the in-hospital intubation rate. The proportion of physiological responders to APP and the in-hospital mortality were reported as secondary outcomes. In conformity with established custom in the ARDS literature, responders were defined by an increase of $\mathrm{P}_{\mathrm{aO}_{2}} / \mathrm{F}_{\mathrm{IO}_{2}}$ ratio $\geq 20 \%$. ${ }^{13}$ When the $\mathrm{P}_{\mathrm{aO}} / \mathrm{F}_{\mathrm{IO}_{2}}$ was not reported, an increase of $\mathrm{S}_{\mathrm{pO}_{2}} / \mathrm{F}_{\mathrm{IO}_{2}}$ ratio $\geq 20 \%$ was considered as a response given the linear relationship between the 2 ratios. ${ }^{14,15}$ In-hospital mortality was reported as an exploratory secondary outcome, as it is a complex outcome that is modulated by multiple individual and population-level confounders.

For dichotomous outcomes, we pooled proportions using a logit transformation with 95\% CI. We assessed statistical heterogeneity by visual inspection of the forest plots and by calculating the $\mathrm{Q}$ and $\mathrm{I}^{2}$ statistics, which were interpreted according to conventional thresholds. For all analyses, we implemented random-effects models with inverse variance weighting, providing that at least 3 studies were available.

Potential sources of heterogeneity or inconsistency included baseline disease severity in terms of $\mathrm{P}_{\mathrm{aO}_{2}} / \mathrm{F}_{\mathrm{IO}_{2}}$ at the initiation of therapy, duration of APP, the timing of

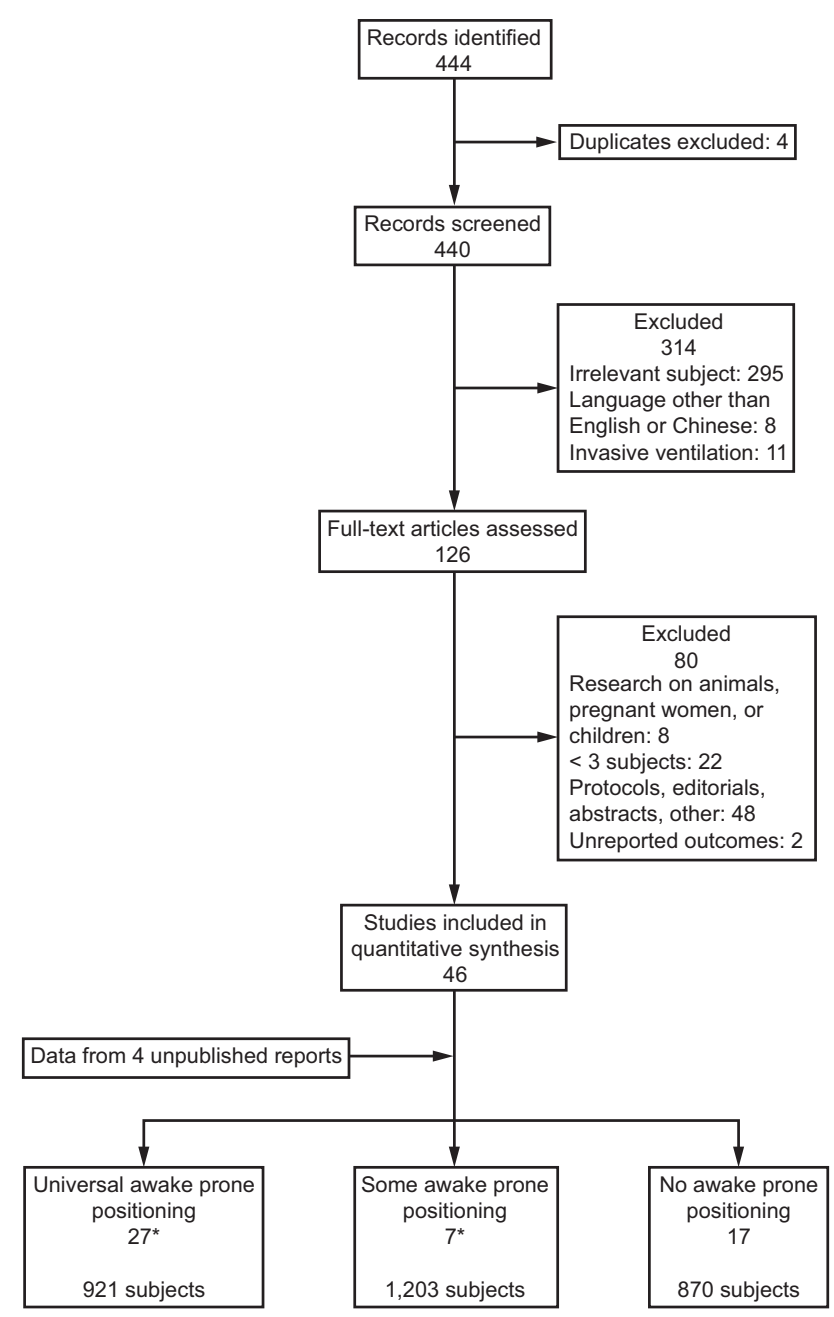

Fig. 1. Flow chart. *One paper reported on both subgroups and is thus counted twice.

APP initiation, and the type of respiratory support (ie, conventional oxygen therapy, HFNC, NIV). We investigated the distributions of these characteristics across groups and studies.

We prespecified 3 characteristics in the protocol to be subject to subgroup analyses on the probability of intubation and mortality. When the information was available, we limited the analysis to the studies with $\mathrm{P}_{\mathrm{aO}_{2}} / \mathrm{F}_{\mathrm{IO}_{2}}<150 \mathrm{~mm}$ $\mathrm{Hg}$ versus $\geq 150 \mathrm{~mm} \mathrm{Hg}$ and according to respiratory support devices (HFNC vs CPAP/NIV). The cutoff value of $\mathrm{P}_{\mathrm{aO}_{2}} / \mathrm{F}_{\mathrm{IO}_{2}}<150 \mathrm{~mm} \mathrm{Hg}$ was based on the previously described survival benefit when these subjects were managed with intubation, as compared to a noninvasive strategy with a high chance of failure. ${ }^{16}$ The third subgroup analysis was limited to studies in the group of APP, in which we analyzed the relationship between APP duration and the probability of intubation and mortality. Up to 0.6 statistically significant interaction tests $(P<.05)$ would be expected on chance alone. 


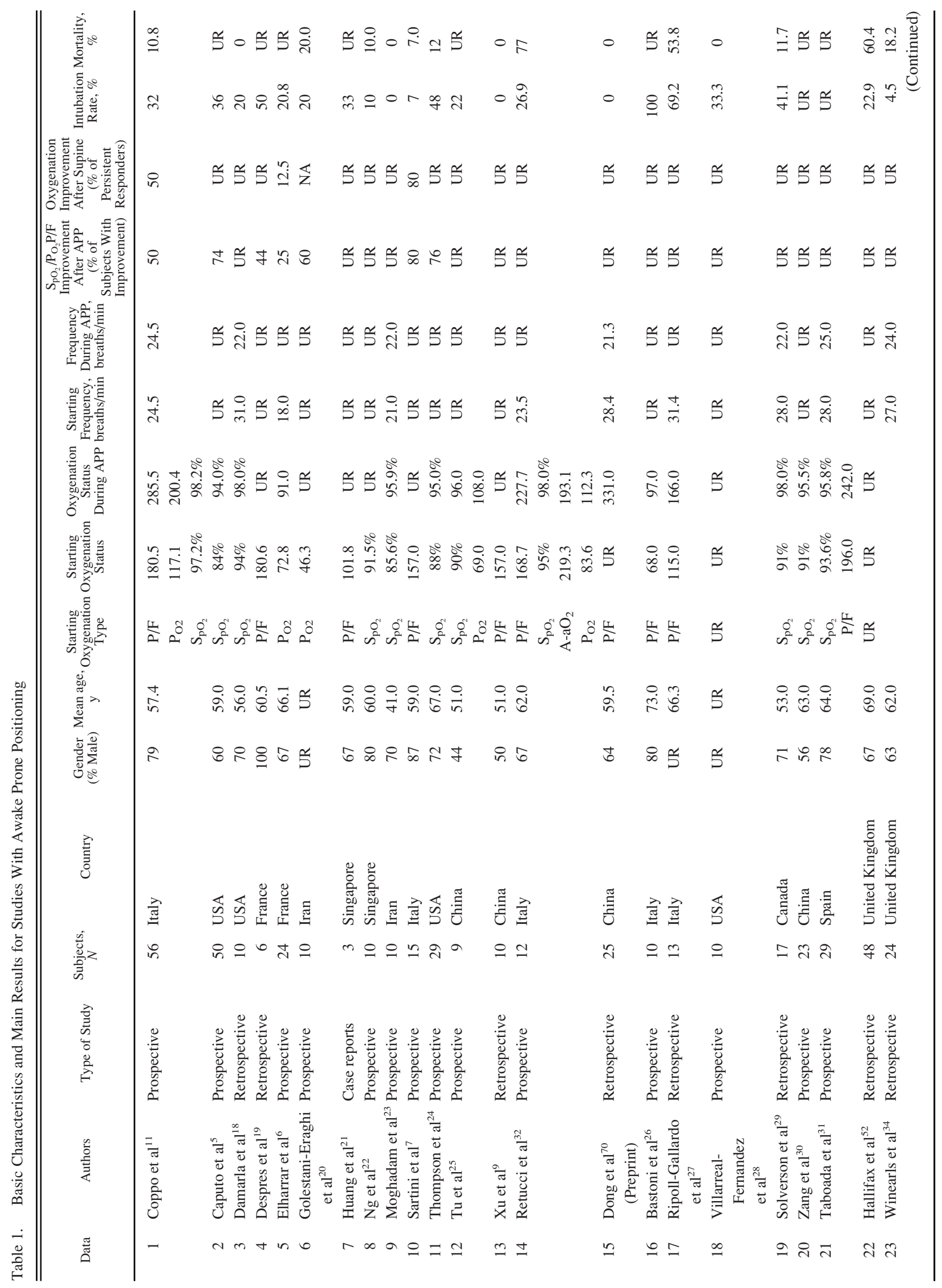




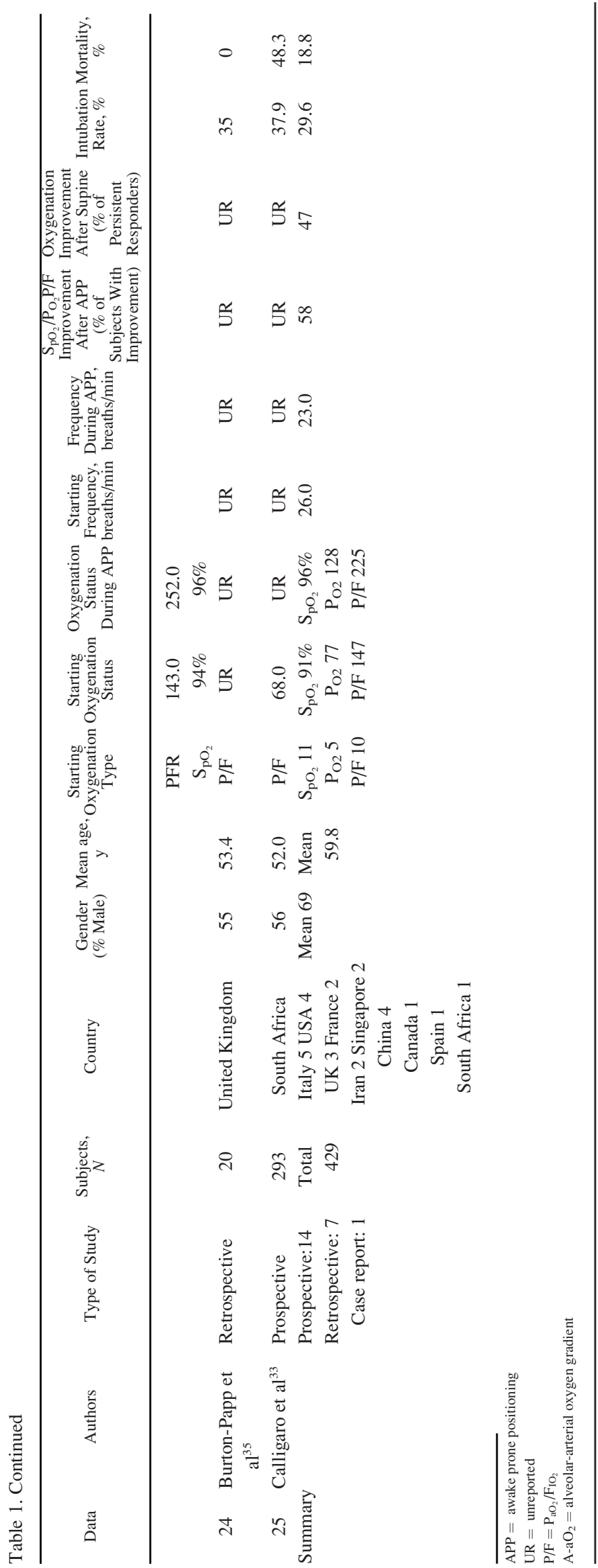

We did not formally assess bias of included studies, as all of them were observational and inherently highly biased. We did not produce a funnel plot, as this method is inaccurate for meta-analyses of proportion studies. ${ }^{17}$

\section{Post Hoc Comparator Groups}

While collecting data, and before carrying out any analyses, we realized that only a minority of identified papers reported on pure populations in which either all subjects were subjected to APP or none was. We, therefore, decided to group subjects into 3 groups a priori: (1) APP when all subjects were proned, (2) some APP when some (at least $10 \%$ ) but not all subjects were proned, and (3) no APP when no subjects were proned $(<10 \%)$. Papers that focused on APP were classified as APP, regardless of the number or proportion of subjects that was able to remain in prone position (PP). We compared subjects treated with APP (group 1) with those not treated with APP (group 3), and we finally reported the $P$ value associated with the test for subgroup differences between group 1 and group 3 . All analyses were performed in $\mathrm{R}$ version 3.6.3 (R Foundation for Statistical Computing, Vienna, Austria) with the help of meta package.

\section{Results}

Our search strategy identified 173 publications on the subject of APP (Fig. E1 in the online supplement, see the related supplementary materials at http://www.rcjournal.com) and 271 papers on the subject of noninvasive oxygenation modalities (Fig. E2 in the online supplement, see the related supplementary materials at http:/www.rcjournal.com) in severe COVID-19. Thus, a total of 444 potentially relevant publications were identified, and 440 were screened for inclusion after removal of duplicates (Fig. 1). After full-text review, 46 published studies ${ }^{5-7,9,11,18-57}$ and data from 4 unpublished data sets were included in the final review, with a combined 2,994 subjects: 921 treated with APP, 870 treated without APP, and a group of 1,203 in whom a significant proportion was treated with APP (Fig. 1, Table 1, and Tables E1 and E2 in the online supplement, see the related supplementary materials at http:// www.rcjournal.com). Clarifications and supplementary materials were obtained from 18 corresponding authors.

\section{Physiological Response to Awake Prone Positioning}

Nineteen studies $(n=381)$ reported on the physiological responses to APP. APP resulted in improved $\mathrm{S}_{\mathrm{pO}_{2}}$ or $\mathrm{P}_{\mathrm{aO}}$ in all 13 studies $(n=271)$ that reported on changes in oxygenation.

Ten studies $(n=198)$ reported on changes in the $\mathrm{P}_{\mathrm{aO}} / \mathrm{F}_{\mathrm{IO}_{2}}$ ratio; of them, $9(n=192)$ reported significant improvement in $\mathrm{P}_{\mathrm{aO}_{2}} / \mathrm{F}_{\mathrm{IO}_{2}}$ ratios with APP. Mean improvement was greater than our predefined threshold of $\geq 20 \%$ in all 7 studies in which changes of $\mathrm{P}_{\mathrm{aO}_{2}} / \mathrm{F}_{\mathrm{IO}_{2}}$ ratios were 


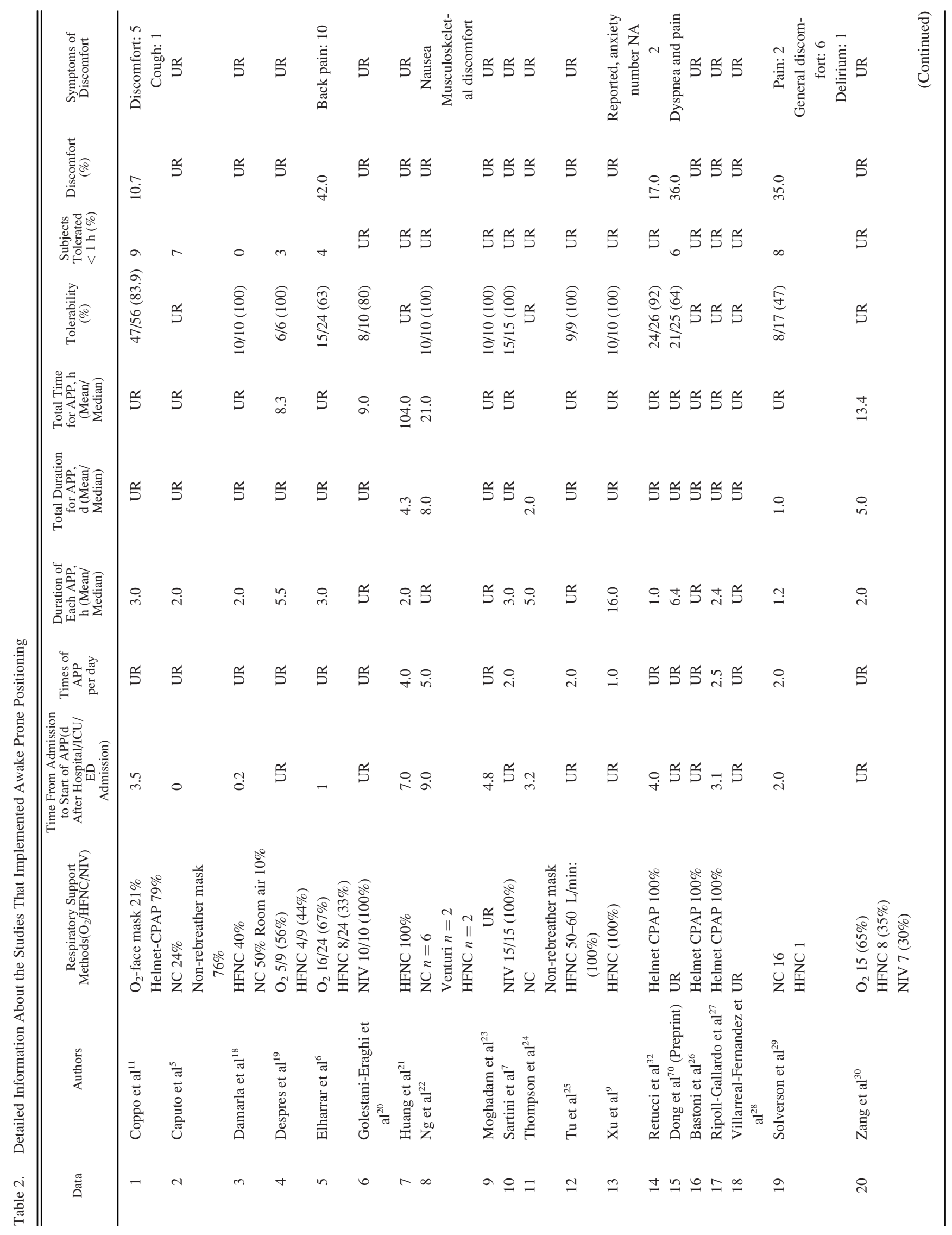




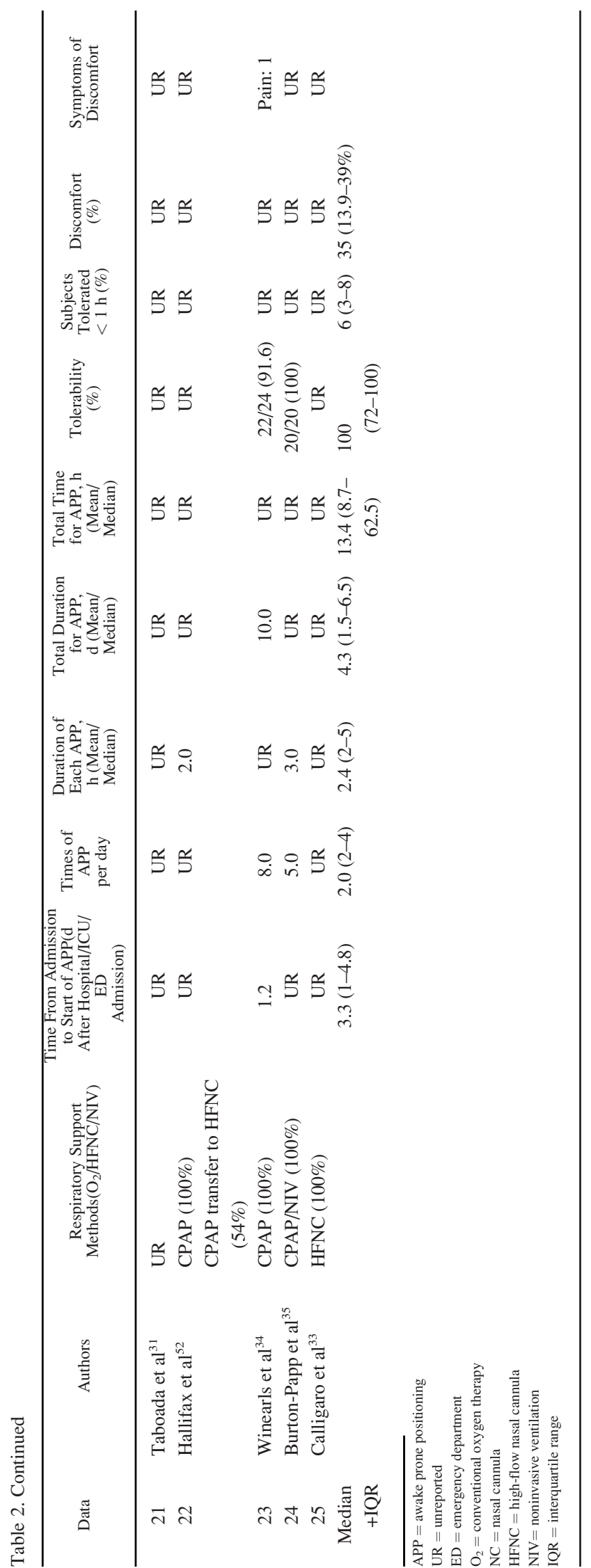

reported in sufficient detail. In 3 studies $(n=72)$, the improvement of the $\mathrm{P}_{\mathrm{aO}} / \mathrm{F}_{\mathrm{IO}_{2}}$ ratio was sustained even after the subjects returned to the supine position ${ }^{31,34,35}$; one study $(n=46)$ demonstrated sustained improvement in only $50 \%$ of subjects ${ }^{11}$; and in another report $(n=26)$, improvement of $\mathrm{P}_{\mathrm{aO}_{2}} / \mathrm{F}_{\mathrm{IO}_{2}}$ was lost after returning to supine position. ${ }^{32}$

Reduction of breathing frequency with APP was demonstrated in 5 studies $(n=90)^{7,18,29,30}$ but not in 2 other studies $(n=34) .{ }^{23,34}$ Finally, significantly reduced $\mathrm{P}_{\mathrm{aCO}}$ was demonstrated only in a single small study $(n=9)^{25}$, whereas no changes in $\mathrm{P}_{\mathrm{aCO}}$ were observed in a larger report $(n=46) .{ }^{11}$

\section{Probability of Intubation With Awake Prone Positioning}

Data on intubation rate were available for 870 subjects treated with APP (23 published studies, $n=717 ; 2$ unpublished studies, $n=153$ ) and for 852 subjects treated with HFNC or CPAP or NIV without APP (16 published studies, $n=645 ; 2$ unpublished studies, $n=207)$. In the APP group, $27 \%$ (95\% CI 19-37\%) required intubation and mechanical ventilation, as compared to $30 \%$ (95\% CI 20 $42 \%$ ) in the control group (Fig. 2). This difference was not statistically significant $(P=.71)$. Subgroup analyses, with stratification according to the duration of APP $(<4$ h daily vs $\geq 4$ h daily), the device (HFNC vs CPAP vs NIV), and the severity of the ARDS $\left(\mathrm{P}_{\mathrm{aO}_{2}} / \mathrm{F}_{\mathrm{IO}_{2}}<150 \mathrm{~mm} \mathrm{Hg}\right.$ vs $\mathrm{P}_{\mathrm{aO}_{2}} / \mathrm{F}_{\mathrm{IO}_{2}} \geq 150 \mathrm{~mm} \mathrm{Hg}$ ), did not demonstrate any significant difference in intubation rate between subjects who were treated with APP and those who were not (Fig. 3).

\section{Probability of Death With Awake Prone Positioning}

Mortality data were available for 767 subjects treated with APP (18 published studies, $n=614 ; 2$ unpublished studies, $n=153$ ) and for 761 subjects treated with HFNC or CPAP or NIV without APP (12 published studies, $n=554$; 2 unpublished studies, $n=207$ ). The mortality rate was $11 \%$ (95\% CI 6-20\%) in subjects treated with APP, as compared to $22 \%$ (95\% CI 13-36\%) in subjects treated with usual care (Fig. 4). This difference was not statistically significant $(P=$ .10). Outcomes were highly heterogeneous between studies, and subgroup analyses did not demonstrate any significant differences in mortality across predetermined subgroups (Fig. 5) and did not identify a subgroup in which APP was associated with statistically significant reduction of mortality.

\section{Tolerability and Comfort of Awake Prone Positioning}

Fifteen studies reported subjects' tolerability to APP, varying from $47-100 \%$. Eight papers reported on subjects' discomfort while in PP, including back pain, dyspnea, and general discomfort. The daily duration of APP was reported in 17 papers $(n=366)$. In 9 papers $(n=201)$, subjects tolerated APP for $<4 \mathrm{~h}$ daily. A single paper reported on a 


\section{Awake Prone Positioning In COVID-19}

Study

No prone positioning

Biez et al

Burns et $\mathrm{al}^{47}$

Duca et $a^{50}$

Geng et $\mathrm{al}^{37}$

He et $\mathrm{al}^{47}$

Hernandez-Romieu et $\mathrm{al}^{44}$

Knights et al ${ }^{49}$

Oranger et al ${ }^{48}$

Patel et al ${ }^{39}$

Sivaloganathan et $\mathrm{al}^{51}$

Vianello et $\mathrm{al}^{40}$

Wang et $\mathrm{al}^{38}$

Xia et $\mathrm{al}^{43}$

Zucman et al ${ }^{41}$

Unpublished data from Duan et al (China)

Unpublished data from UChicago Medicine

Random effects model

Heterogeneity: $R^{2}=90 \%, \tau^{2}=0.9432, P<.01$

Prone positioning

Bastoni et $\mathrm{al}^{26}$

Burton-Papp et al ${ }^{35}$

Calligaro et $\mathrm{al}^{33}$

Caputo et $\mathrm{al}^{5}$

Coppo et al ${ }^{11}$

Damarla et al ${ }^{18}$

Despres et al ${ }^{19}$

Dong et $\mathrm{al}^{70}$ (Preprint)

Elharrar et $\mathrm{al}^{6}$

Ferrando et $\mathrm{al}^{36}$

Golestani-Eraghi et al

Huang et al ${ }^{18}$

Moghadam et $\mathrm{al}^{19}$

$\mathrm{Ng}$ et $\mathrm{al}^{22}$

Retucci et al. ${ }^{32}$

Ripoll-Gallardo et al $^{7}$

Sartini et $\mathrm{al}^{7}$

Solverson et $\mathrm{al}^{29}$

Thompson et $\mathrm{al}^{24}$

Tu et al2 $2^{5}$

Villarreal-Fernandez et $\mathrm{al}^{28}$

Winearls et $\mathrm{al}^{34}$

Xu et al ${ }^{9}$

Unpublished data from the Irish awake proning group Unpublished data from Unity Point Health

Random effects model

Heterogeneity: $R^{2}=85 \%, \tau^{2}=0.9138, P<.01$

Heterogeneity: $R=88 \%, \tau^{2}=0.9311, P<.01$

Test for subgroup differences: $X_{1}^{2}=0.14, \mathrm{df}=1(P=.71)$
Intubations Total

Proportion $(95 \% \mathrm{Cl})$

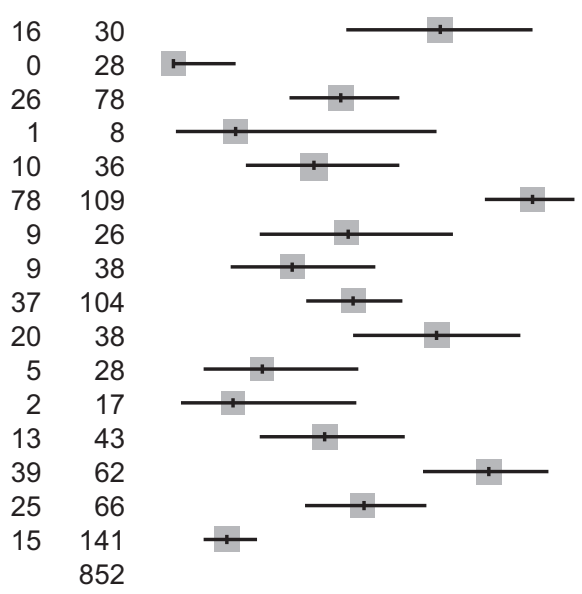

$0.53(0.34-0.72)$

$0.00(0.00-0.12)$

$0.33(0.23-0.45)$

$0.12(0.00-0.53)$

$0.28(0.14-0.45)$

$0.72(0.62-0.80)$

$0.35(0.17-0.56)$

$0.24(0.11-0.40)$

$0.36(0.26-0.46)$

$0.53(0.36-0.69)$

$0.18(0.06-0.37)$

$0.12(0.01-0.36)$

$0.30(0.17-0.46)$

$0.63(0.50-0.75)$

$0.38(0.26-0.51)$

$0.11(0.06-0.17)$

$0.30(0.20-0.42)$
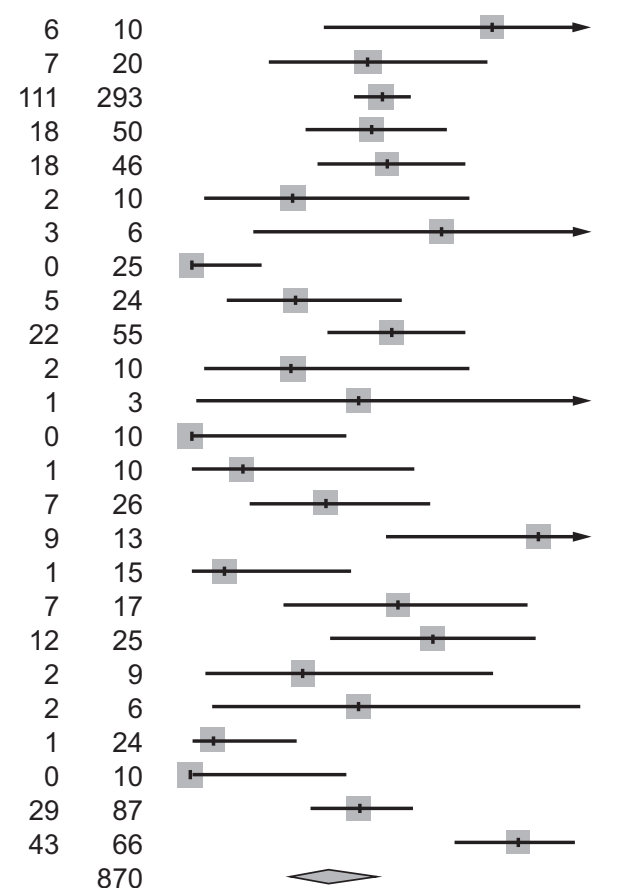

$0.60(0.26-0.88)$

$0.35(0.15-0.59)$

$0.38(0.32-0.44)$

$0.36(0.23-0.51)$

$0.39(0.25-0.55)$

$0.20(0.03-0.56)$

$0.50(0.12-0.88)$

$0.00(0.00-0.14)$

$0.21(0.07-0.42)$

$0.40(0.27-0.54)$

$0.20(0.03-0.56)$

$0.33(0.01-0.91)$

$0.00(0.00-0.31)$

$0.10(0.00-0.45)$

$0.27(0.12-0.48)$

$0.69(0.39-0.91)$

$0.07(0.00-0.32)$

$0.41(0.18-0.67)$

$0.48(0.28-0.69)$

$0.22(0.03-0.60)$

$0.33(0.04-0.78)$

$0.04(0.00-0.21)$

$0.00(0.00-0.31)$

$0.33(0.24-0.44)$

$0.65(0.52-0.76)$

$0.27(0.19-0.37)$

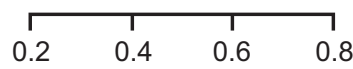

Proportion of outcome occurrence

Fig. 2. Association between awake prone positioning and intubation in each report and overall. A meta-analysis of pooled proportion demonstrating the intubation rate for studies describing subjects who did or did not undergo prone positioning.

cohort of 55 subjects who were able to achieve APP for more than 16 h daily. ${ }^{36}$

\section{Discussion}

Our systematic review of proportional outcomes from observational studies demonstrated that APP improved oxygenation but did not show benefit for the frequency of intubation or mortality in subjects with acute hypoxemic respiratory failure secondary to COVID-19. The main strength of our study was that it was the first report focused on effect of APP on intubation rate with a comparison with the data from population treated with usual care during the similar time period within the first wave of pandemic. Our 
Awake Prone Positioning In COVID-19

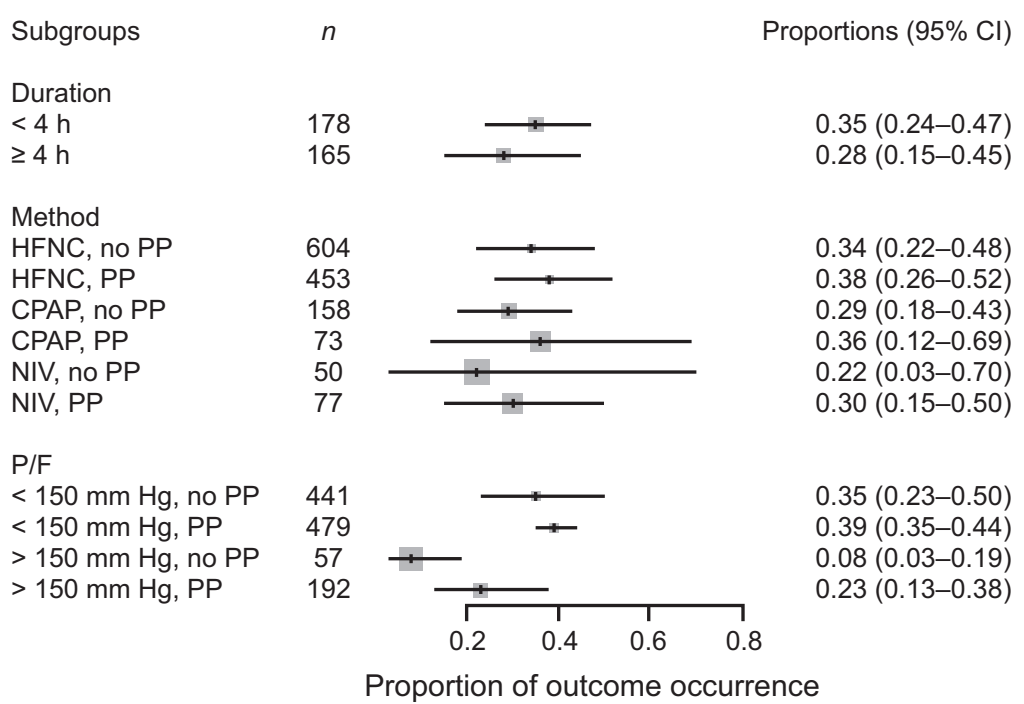

Fig. 3. Association between awake prone positioning and intubation within subgroups defined by the duration of proning, the type of respiratory support device, and the $\mathrm{P}_{\mathrm{aO}_{2}} / \mathrm{F}_{\mathrm{IO}_{2}}$ ratio at enrollment. A meta-analysis of pooled proportion of intubation for studies reporting time spent in prone position ( $<$ or $>4 \mathrm{~h}$ ), oxygen delivery device (HFNC, CPAP), and degree of hypoxemia ( $\mathrm{P} / \mathrm{F}<$ or $>150 \mathrm{~mm} \mathrm{Hg}$ ) for studies describing subjects who did not undergo prone positioning and studies that reported in subjects who underwent prone positioning. HFNC $=$ high-flow nasal cannula, $\mathrm{PP}=$ prone position, $\mathrm{NIV}=$ noninvasive ventilation, $\mathrm{P} / \mathrm{F}=\mathrm{P}_{\mathrm{aO}_{2}} / \mathrm{F}_{\mathrm{IO}_{2}}$ ratio.

study also had a large sample size, with a total of 921 subjects treated with APP.

We found that APP improved oxygenation parameters, and this improvement was sustained even after subjects returned to the supine position in 3 studies. ${ }^{31,34,35}$ APP was also associated with reduced breathing frequency, and good tolerability was reported with the use of various modalities of respiratory support, including conventional oxygen therapy, HFNC, and CPAP or NIV that was delivered through either a helmet or full face mask. Improvement in oxygenation with APP can be explained by the correction of ventilation-perfusion mismatch, ${ }^{8}$ better lung recruitment, and reduction of alveolar strain. ${ }^{4}$ However, improvements in oxygenation do not guarantee better clinical outcomes. For instance, improvements of $\mathrm{P}_{\mathrm{aO}} / \mathrm{F}_{\mathrm{IO}_{2}}$ ratio do not correlate with mortality in intubated patients subjected to prone positioning. ${ }^{58}$ More physiological and clinical studies are needed to delineate the relationship between improvement of oxygenation parameters and clinical outcomes in patients with COVID-19.

Contrary to previous reports, ${ }^{24,59}$ we did not find that APP reduced intubation rates. Several reasons can be advanced to explain this lack of efficacy. First, intubation criteria were not uniformly defined across studies and involved the treating physician's subjective judgment. During the pandemic, the recommended respiratory support strategies evolved from early aggressive intubation to strategies of respiratory support designed to prevent intubation. ${ }^{5,44,60-62}$ Second, the timing of APP initiation, either as an adjunctive (early) or rescue (late) therapy, may influence intubation rate. The use of APP at an early stage $\left(\mathrm{P}_{\mathrm{aO}_{2}} / \mathrm{F}_{\mathrm{IO}_{2}}\right.$ ratio $>150 \mathrm{~mm} \mathrm{Hg}$ ) may be better tolerated, result in better oxygenation, and protect patients from self-induced lung injury and thus prevent further disease progression. ${ }^{63,64}$ However, in our meta-analysis of proportions, we did not detect a signal of benefit of APP in the subgroup of subjects with $\mathrm{P}_{\mathrm{aO}_{2}} / \mathrm{F}_{\mathrm{IO}_{2}}$ ratio $>150 \mathrm{~mm} \mathrm{Hg}$. Third, the duration of APP might have a dose-response relationship, and it is possible that a reduction in the rate of intubations could be seen only in subjects who were subjected to longer periods of APP. Our subgroup analyses did not demonstrate significantly lower intubation rates for subjects who remained in PP for longer periods of time, but it could be argued that our analysis was underpowered, as only 2 studies $(n=65)$ reported daily APP periods $>16$ h. ${ }^{9,36}$ Fourth, intubation might be inevitable as the disease progresses, despite initial and sustained improvement in oxygenation. It has been argued that intubation rates are lower in patients who experience sustained improvement in oxygenation after APP, the so-called responders. ${ }^{35}$ However, this finding has not been replicated in other retrospective studies ${ }^{11}$ and could be the result of simple reverse causality, with patients responding to APP because of their already favorable clinical course. Finally, an unknown proportion of subjects with donot-intubate orders was included in both groups, which could have diluted any possible benefit of APP.

We did not demonstrate a signal of reduced mortality with APP. Given the complex relationship between disease severity, individual comorbidities, socioeconomic status, and variable access to quality care during a pandemic, this 
Study

No prone positioning

Burns et $a^{47}$

Duca et $\mathrm{a}^{50}$

Geng et $\mathrm{al}^{37}$

$\mathrm{He}$ et $\mathrm{a}^{45}$

Hernandez-Romieu et al ${ }^{44}$

Knights et al ${ }^{49}$

Oranger et $\mathrm{a}^{48}$

Pagano et al ${ }^{46}$

Patel et al ${ }^{39}$

Sivaloganathan et al ${ }^{51}$

Vianello et $a^{40}$

Xia et al ${ }^{43}$

Unpublished data from Duan et al (China)

Unpublished data from UChicago Medicine

Random effects model

Heterogeneity: $R^{R}=92 \%, \tau^{2}=1.3768, P<.01$

Prone positioning

Burton-Papp et al ${ }^{35}$

Calligaro et $\mathrm{al}^{33}$

Coppo et al11

Damarla et al

Dong et $\mathrm{al}^{70}$ (Preprint)

Ferrando et al ${ }^{36}$

Golestani-Eraghi et al20

Moghadam et al ${ }^{23}$

$\mathrm{Ng}$ et $\mathrm{al}^{22}$

Retucci et al ${ }^{32}$

Ripoll-Gallardo et al ${ }^{27}$

Sartini et $\mathrm{al}^{7}$

Solverson et al ${ }^{29}$

Thompson et $\mathrm{al}^{24}$

Villarreal-Fernandez et $\mathrm{al}^{28}$

Winearls et $a^{34}$

Xu et al ${ }^{9}$

Zang et al ${ }^{30}$

Unpublished data from the Irish awake proning group

Unpublished data from Unity Point Health

Random effects model

Heterogeneity: $P^{R}=87 \%, \tau^{2}=1.4291, P<.01$

Heterogeneity: $R=91 \%, \tau^{2}=1.5466, P<.01$

Test for subgroup differences: $X_{1}^{2}=2.78, \mathrm{df}=1(P=.10)$
Deaths Total

Proportion $(95 \% \mathrm{Cl})$
$0.50(0.31-0.69)$

$0.74(0.63-0.84)$

$0.00(0.00-0.37)$

$0.28(0.14-0.45)$

$0.22(0.15-0.31)$

$0.27(0.12-0.48)$

$0.00(0.00-0.09)$

$0.61(0.36-0.83)$

$0.14(0.08-0.23)$

$0.08(0.02-0.21)$

$0.11(0.02-0.28)$

$0.30(0.17-0.46)$

$0.21(0.12-0.33)$

$0.25(0.18-0.33)$

$0.22(0.13-0.36)$

$0.00(0.00-0.17)$

$0.48(0.42-0.54)$

$0.11(0.04-0.24)$

$0.00(0.00-0.31)$

$0.00(0.00-0.14)$

$0.15(0.06-0.27)$

$0.20(0.03-0.56)$

$0.00(0.00-0.31)$

$0.10(0.00-0.45)$

$0.08(0.01-0.25)$

$0.54(0.25-0.81)$

$0.07(0.00-0.32)$

$0.12(0.01-0.36)$

$0.12(0.03-0.31)$

$0.00(0.00-0.46)$

$0.17(0.05-0.37)$

$0.00(0.00-0.31)$

$0.43(0.23-0.66)$

$0.08(0.03-0.16)$

$0.39(0.28-0.52)$

$0.11(0.06-0.20)$

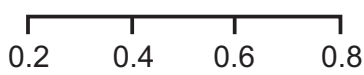

Proportion of outcome occurrence

Fig. 4. Association between awake prone positioning and mortality in each report and overall. A meta-analysis of pooled proportion demonstrating the intubation rate for studies describing subjects who did or did not undergo prone positioning.

finding should be interpreted as exploratory. Due to the retrospective nature of included studies, selection biases are very likely. The type of respiratory support (conventional oxygen therapy, HFNC, CPAP/NIV delivered through a conventional mask vs a helmet) was not balanced between subjects treated with APP and those who were not. Analyses with stratification by the type of respiratory support device did not demonstrate significant subgroup differences in mortality. These subgroup analyses were severely limited by the fact that we only included observational studies in our analysis; had access only to overall group statistics, not individual patient data; and a proportion of subjects were treated with various devices through the course of their disease.

Our study has several limitations. First, data were available only from a group of relatively heterogeneous observational studies. Significant levels of inclusion bias are also likely to be present. Without individual patient data, we could not account for the many uncontrolled differences between subjects treated with APP and those who received usual care. Some subjects were subjected to APP in extremis after failing usual care and could have been sicker 
Awake Prone Positioning In COVID-19

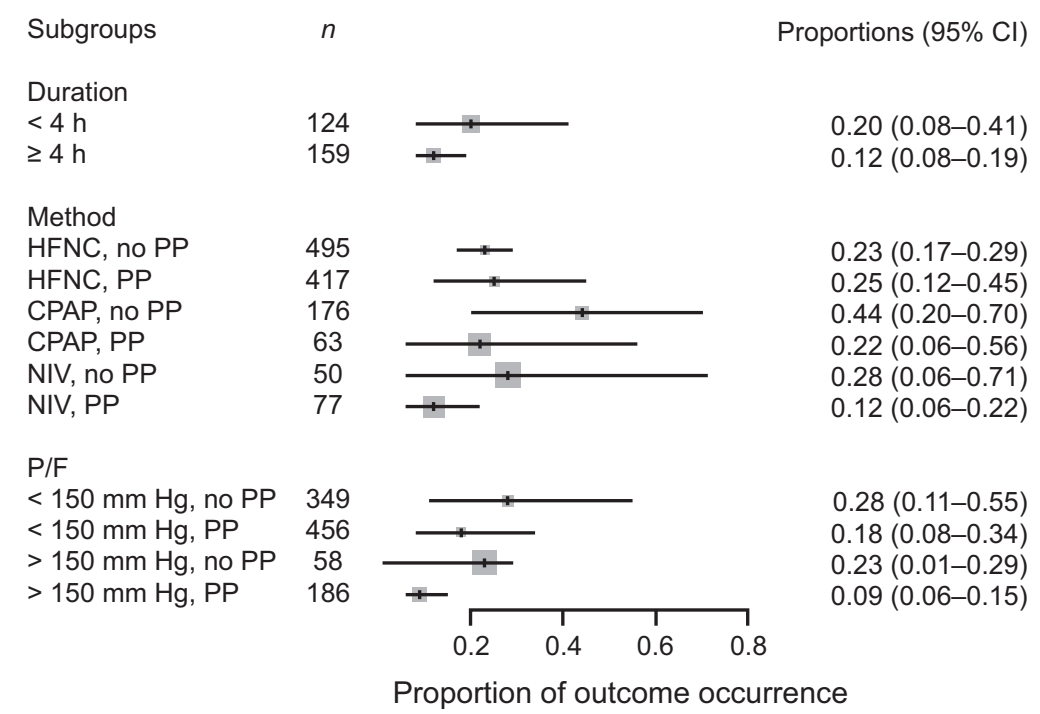

Fig. 5. Association between awake prone positioning and mortality, within subgroups defined by the duration of proning, the type of respiratory support device, and the $\mathrm{P}_{\mathrm{aO}} / \mathrm{F}_{\mathrm{IO}_{2}}$ at enrollment. A meta-analysis of pooled proportion of mortality for studies reporting time spent in prone position ( $<$ or $>4 \mathrm{~h}$ ), oxygen delivery device (HFNC, CPAP), and degree of hypoxemia (P/F $<$ or $>150 \mathrm{~mm} \mathrm{Hg}$ ) for studies describing subjects who did not undergo prone positioning and studies that reported in subjects who underwent prone positioning. HFNC $=$ high-flow nasal cannula, $\mathrm{PP}=$ prone position, $\mathrm{NIV}=$ noninvasive ventilation, $\mathrm{P} / \mathrm{F}=\mathrm{P}_{\mathrm{aO}_{2}} / \mathrm{F}_{\mathrm{IO}_{2}}$ ratio.

than subjects included in cohorts without APP. Conversely, in other reports, only subjects who could self-prone were treated with APP, and these were likely less sick than those in the control group. Second, a variety of respiratory support devices, including helmet CPAP, was used in both groups. It is not known whether the choice of the device has an impact on outcomes in patients with severe COVID-19. Third, outcomes were highly heterogeneous, which likely reflects populations with various disease severities, various comorbid conditions, as well as geographical variations of care for patients with ARDS. ${ }^{65}$ Fourth, we included unpublished, non-peer-reviewed data. However, our findings remained robust with the exclusion of unpublished data. Fifth, the mortality rate in our studies is lower than reported in other large cohorts, ${ }^{66-68}$ which suggests selection and publication bias, which would be expected to be in favor of APP. Sixth, we were not able to control for the use of evidence-based treatments such as corticosteroids. However, all included reports finished enrollment before the benefit of corticosteroids was demonstrated $^{69}$ and when their use was indeed actively discouraged. Seventh, only a minority of subjects were able to tolerate longer periods of APP, and it can be argued that the duration of APP was not sufficient to generate a clinically meaningful change in outcomes. However, a physiologically effective but clinically intolerable intervention would remain ineffective overall. Eighth, data for other important outcomes, such as the number of ventilator-free days or the ICU length of stay, were not available for analysis. Finally, all included studies were performed during the initial months of the pandemic. At that time, most groups were not experienced with APP. We may imagine that APP would be more effective after the learning period when patient selection, positioning, monitoring, and duration of session are more established. Most of these subjects were infected with the initial virus. The efficacy of APP may be different in variants, and the effect of APP may be higher as clinicians gain experience with this technique.

\section{Conclusions}

In summary, available evidence from observational studies suggests that APP improves oxygenation, but these improvements do not appear to translate into reduced rates of intubation at the first wave of pandemic real-world practice. We did not find any obvious signals of harm, and we did not see any worrisome signal in mortality. The high selectivity of subjects, the inconsistency in the application of prone positioning in published reports, and the heterogeneity of outcomes emphasize the need for randomized controlled trials, as a clinically important benefit cannot be excluded based on available low-quality data. Given the promising benefit of APP on intubation, trials should endeavor to include patients with different disease severity, managed with a uniform strategy of respiratory support, and with clear criteria for intubation.

\section{REFERENCES}

1. Ziehr DR, Alladina J, Petri CR, Maley JH, Moskowitz A, Medoff BD, et al. Respiratory pathophysiology of mechanically ventilated patients with COVID-19: a cohort study. Am J Respir Crit Care Med 2020;201 (12):1560-1564. 
2. Guerin C, Reignier J, Richard JC, Beuret P, Gacouin A, Boulain T, et al. Prone positioning in severe acute respiratory distress syndrome. N Engl J Med 2013;368(23):2159-2168.

3. Sud S, Friedrich JO, Adhikari NK, Taccone P, Mancebo J, Polli F, et al. Effect of prone positioning during mechanical ventilation on mortality among patients with acute respiratory distress syndrome: a systematic review and meta-analysis. CMAJ 2014;186(10):E381-390.

4. Kallet RH. A comprehensive review of prone position in ARDS. Respir Care 2015;60(11):1660-1687.

5. Caputo ND, Strayer RJ, Levitan R. Early self-proning in awake, nonintubated patients in the emergency department: a single ED's experience during the COVID-19 pandemic. Acad Emerg Med 2020;27 (5):375-378.

6. Elharrar X, Trigui Y, Dols AM, Touchon F, Martinez S, Prud'homme $\mathrm{E}$, et al. Use of prone positioning in non-intubated patients with COVID-19 and hypoxemic acute respiratory failure. JAMA 2020;323 (22):2336-2338.

7. Sartini C, Tresoldi M, Scarpellini P, Tettamanti A, Carco F, Landoni $\mathrm{G}$, et al. Respiratory parameters in patients with COVID-19 after using noninvasive ventilation in the prone position outside the intensive care unit. JAMA 2020;323(22):2338-2340.

8. Zarantonello F, Andreatta G, Sella N, Navalesi P. Prone position and lung ventilation/perfusion matching in acute respiratory failure due to COVID-19. Am J Respir Crit Care Med 2020;202(2):278-279.

9. Xu Q, Wang T, Qin X, Jie Y, Zha L, Lu W. Early awake prone position combined with high-flow nasal oxygen therapy in severe COVID19: a case series. Crit Care 2020;24(1):250.

10. Slessarev M, Cheng J, Ondrejicka M, Arntfield R; Critical Care Western Research Group. Patient self-proning with high-flow nasal cannula improves oxygenation in COVID-19 pneumonia. Can J Anaesth 2020.

11. Coppo A, Bellani G, Winterton D, Di Pierro M, Soria A, Faverio P, et al. Feasibility and physiological effects of prone positioning in nonintubated patients with acute respiratory failure due to COVID-19 (PRON-COVID): a prospective cohort study. Lancet Respir Med 2020.

12. Moher D, Liberati A, Tetzlaff J, Altman DG, Group P; PRISMA Group. Preferred reporting items for systematic reviews and metaanalyses: the PRISMA statement. PLoS Med 2009;6(7):e1000097.

13. Lemasson S, Ayzac L, Girard R, Gaillard S, Pavaday K, Guerin C. Does gas exchange response to prone position predict mortality in hypoxemic acute respiratory failure? Intensive Care Med 2006;32 (12): 1987-1993.

14. Rice TW, Wheeler AP, Bernard GR, Hayden DL, Schoenfeld DA, Ware LB. Comparison of the $\mathrm{S}_{\mathrm{pO} 2} / \mathrm{F}_{\mathrm{IO} 2}$ ratio and the $\mathrm{P}_{\mathrm{aO} 2} / \mathrm{F}_{\mathrm{IO} 2}$ ratio in patients with acute lung injury or ARDS. Chest 2007;132(2):410-417.

15. Chen W, Janz DR, Shaver CM, Bernard GR, Bastarache JA, Ware LB. Clinical characteristics and outcomes are similar in ARDS diagnosed by oxygen saturation $/ \mathrm{F}_{\mathrm{IO} 2}$ ratio compared with $\mathrm{P}_{\mathrm{aO} 2} / \mathrm{F}_{\mathrm{IO} 2}$ ratio. Chest 2015;148(6):1477-1483.

16. Bellani G, Laffey JG, Pham T, Madotto F, Fan E, Brochard L, et al; ESICM Trials Group. Noninvasive ventilation of patients with acute respiratory distress syndrome. Insights from the LUNG SAFE study. Am J Respir Crit Care Med 2017;195(1):67-77.

17. Hunter JP, Saratzis A, Sutton AJ, Boucher RH, Sayers RD, Bown MJ. In meta-analyses of proportion studies, funnel plots were found to be an inaccurate method of assessing publication bias. J Clin Epidemiol 2014;67(8):897-903.

18. Damarla M, Zaeh S, Niedermeyer S, Merck S, Niranjan-Azadi A, Broderick B, et al. Prone positioning of non-intubated patients with COVID-19. Am J Respir Crit Care Med 2020;202(4):604-606.

19. Despres C, Brunin Y, Berthier F, Pili-Floury S, Besch G. Prone positioning combined with high-flow nasal or conventional oxygen therapy in severe COVID-19 patients. Crit Care 2020;24(1):256.
20. Golestani-Eraghi M, Mahmoodpoor A. Early application of prone position for management of COVID-19 patients. J Clin Anesth 2020;66:109917.

21. Huang CF, Zhuang YF, Liu J, Tay CK, Sewa DW. Rationale and significance of patient selection in awake prone positioning for COVID19 pneumonia. Eur Respir J 2020;56(3).

22. Ng Z, Tay WC, Ho CHB. Awake prone positioning for non-intubated oxygen-dependent COVID-19 pneumonia patients. Eur Respir J 2020;56(1).

23. Moghadam VD, Shafiee H, Ghorbani M, Heidarifar R. Prone positioning in management of COVID-19 hospitalized patients. Braz J Anesthesiol 2020;70(2):188-190.

24. Thompson AE, Ranard BL, Wei Y, Jelic S. Prone positioning in awake, non-intubated patients with COVID-19 hypoxemic respiratory failure. JAMA Intern Med 2020;180(11):1537-1539.

25. Tu GW, Liao YX, Li QY, Dong H, Yang LY, Zhang XY, et al. Prone positioning in high-flow nasal cannula for COVID-19 patients with severe hypoxemia: a pilot study. Ann Transl Med 2020;8(9):598.

26. Bastoni D, Poggiali E, Vercelli A, Demichele E, Tinelli V, Iannicelli $\mathrm{T}$, et al. Prone positioning in patients treated with noninvasive ventilation for COVID-19 pneumonia in an Italian emergency department. Emerg Med J 2020;37(9):565-566.

27. Ripoll-Gallardo A, Grillenzoni L, Bollon J, Della Corte F, BaroneAdesi F. Prone positioning in non-intubated patients with COVID-19 outside of the intensive care unit: more evidence needed. Disaster Med Public Health Prep 2020;14(4):e22-e24.

28. Villarreal-Fernandez E, Patel R, Golamari R, Khalid M, DeWaters A, Haouzi P. A plea for avoiding systematic intubation in severely hypoxemic patients with COVID-19-associated respiratory failure. Crit Care 2020;24(1):337.

29. Solverson K, Weatherald J, Parhar KKS. Tolerability and safety of awake prone positioning COVID-19 patients with severe hypoxemic respiratory failure. Can J Anaesth 2021;68(1):64-70.

30. Zang X, Wang Q, Zhou H, Liu S, Xue X; Group C-EPPS. Efficacy of early prone position for COVID-19 patients with severe hypoxia: a single-center prospective cohort study. Intensive Care Med 2020;46 (10):1927-1929.

31. Taboada M, Rodriguez N, Riveiro V, Baluja A, Atanassoff PG. Prone positioning in awake non-ICU patients with ARDS caused by COVID-19. Anaesth Crit Care Pain Med 2020;39(5):581-583.

32. Retucci M, Aliberti S, Ceruti C, Santambrogio M, Tammaro S, Cuccarini $\mathrm{F}$, et al. Prone and lateral positioning in spontaneously breathing patients with COVID-19 pneumonia undergoing noninvasive helmet CPAP treatment. Chest 2020;158(6):2431-2435.

33. Calligaro GL, Lalla U, Audley G, Gina P, Miller MG, Mendelson M, et al. The utility of high-flow nasal oxygen for severe COVID-19 pneumonia in a resource-constrained setting: a multi-center prospective observational study. EClinicalMedicine 2020;28:100570.

34. Winearls S, Swingwood EL, Hardaker CL, Smith AM, Easton FM, Millington KJ, et al. Early conscious prone positioning in patients with COVID-19 receiving continuous positive airway pressure: a retrospective analysis. BMJ Open Respir Res 2020;7(1).

35. Burton-Papp HC, Jackson AIR, Beecham R, Ferrari M, Nasim-Mohi $\mathrm{M}$, Grocott MPW, et al; REACT COVID Investigators. Conscious prone positioning during noninvasive ventilation in COVID-19 patients: experience from a single center. F1000Res 2020;9:859.

36. Ferrando C, Mellado-Artigas R, Gea A, Arruti E, Aldecoa C, Adalia R, et al; COVID-19 Spanish ICU Network. Awake prone positioning does not reduce the risk of intubation in COVID-19 treated with highflow nasal oxygen therapy: a multi-center, adjusted cohort study. Crit Care 2020;24(1):597.

37. Geng S, Mei Q, Zhu C, Yang T, Yang Y, Fang X, et al. High-flow nasal cannula is a good treatment option for COVID-19. Heart Lung 2020;49(5):444-445. 
38. Wang K, Zhao W, Li J, Shu W, Duan J. The experience of high-flow nasal cannula in hospitalized patients with 2019 novel coronavirusinfected pneumonia in 2 hospitals of Chongqing. Ann Intensive Care 2020;10(1):37.

39. Patel A, Jernigan DB; 2019-nCoV CDC Response Team. Initial public health response and interim clinical guidance for the 2019 novel coronavirus outbreak-United States, December 31, 2019-February 4, 2020. MMWR Morb Mortal Wkly Rep 2020;69(5):140-146.

40. Vianello A, Arcaro G, Molena B, Turato C, Sukthi A, Guarnieri G, et al. High-flow nasal cannula oxygen therapy to treat patients with hypoxemic acute respiratory failure consequent to SARS-CoV-2 infection. Thorax 2020;75(11):998-1000.

41. Zucman N, Mullaert J, Roux D, Roca O, Ricard JD; Contributors. Prediction of outcome of nasal high flow use during COVID-19related acute hypoxemic respiratory failure. Intensive Care Med 2020;46(10):1924-1926.

42. Blez D, Soulier A, Bonnet F, Gayat E, Garnier M. Monitoring of highflow nasal cannula for SARS-CoV-2 severe pneumonia: less is more, better look at respiratory rate. Intensive Care Med 2020;46(11):2094-2095.

43. Xia J, Zhang Y, Ni L, Chen L, Zhou C, Gao C, et al. High-flow nasal oxygen in coronavirus disease 2019 patients with acute hypoxemic respiratory failure: a multi-center, retrospective cohort study. Crit Care Med 2020;48(11):e1079-e1086.

44. Hernandez-Romieu AC, Adelman MW, Hockstein MA, Robichaux CJ, Edwards JA, Fazio JC, et al; Emory COVID-19 Quality and Clinical Research Collaborative. Timing of intubation and mortality among critically ill coronavirus disease 2019 patients: a single-center cohort study. Crit Care Med 2020;48(11):e1045-e1053.

45. He G, Han Y, Fang Q, Zhou J, Shen J, Li T, et al. [Clinical experience of high-flow nasal cannula oxygen therapy in severe COVID-19 patients]. Zhejiang Da Xue Xue Bao Yi Xue Ban 2020;49(2):232-239.

46. Pagano A, Porta G, Bosso G, Allegorico E, Serra C, Dello Vicario F, et al. Noninvasive CPAP in mild and moderate ARDS secondary to SARS-CoV-2. Respir Physiol Neurobiol 2020;280:103489.

47. Burns GP, Lane ND, Tedd HM, Deutsch E, Douglas F, West SD, et al. Improved survival following ward-based noninvasive pressure support for severe hypoxia in a cohort of frail patients with COVID-19: retrospective analysis from a UK teaching hospital. BMJ Open Respir Res 2020;7(1).

48. Oranger M, Gonzalez-Bermejo J, Dacosta-Noble P, Llontop C, Guerder A, Trosini-Desert V, et al. Continuous positive airway pressure to avoid intubation in SARS-CoV-2 pneumonia: a 2-period retrospective case-control study. Eur Respir J 2020.

49. Knights H, Mayor N, Millar K, Cox M, Bunova E, Hughes M, et al. Characteristics and outcomes of patients with COVID-19 at a district general hospital in Surrey, UK. Clin Med 2020;20(5):e148-e153.

50. Duca A, Memaj I, Zanardi F, Preti C, Alesi A, Della Bella L, et al. Severity of respiratory failure and outcome of patients needing a ventilatory support in the emergency department during Italian novel coronavirus SARS-CoV2 outbreak: preliminary data on the role of helmet $\mathrm{CPAP}$ and noninvasive positive pressure ventilation. EClinicalMedicine 2020;24:100419.

51. Sivaloganathan AA, Nasim-Mohi M, Brown MM, Abdul N, Jackson A, Fletcher SV, et al; REACT Investigators. Noninvasive ventilation for COVID-19-associated acute hypoxemic respiratory failure: experience from a single center. Br J Anaesth 2020;125(4):e368-e371.

52. Hallifax RJ, Porter BM, Elder PJ, Evans SB, Turnbull CD, Hynes G, et al. Successful awake proning is associated with improved clinical outcomes in patients with COVID-19: single-center high-dependency unit experience. BMJ Open Respir Res 2020;7(1).

53. Franco C, Facciolongo N, Tonelli R, Dongilli R, Vianello A, Pisani L, et al. Feasibility and clinical impact of out-of-ICU noninvasive respiratory support in patients with COVID-19-related pneumonia. Eur Respir J 2020
54. Demoule A, Vieillard Baron A, Darmon M, Beurton A, Geri G, Voiriot $\mathrm{G}$, et al. High-flow nasal cannula in critically ill severe COVID-19 patients. Am J Respir Crit Care Med 2020;202(7):10391042.

55. Aliberti S, Radovanovic D, Billi F, Sotgiu G, Costanzo M, Pilocane T, et al. Helmet CPAP treatment in patients with COVID-19 pneumonia: a multicenter, cohort study. Eur Respir J 2020

56. Nightingale R, Nwosu N, Kutubudin F, Fletcher T, Lewis J, Frost F, et al. Is continuous positive airway pressure (CPAP) a new standard of care for type 1 respiratory failure in COVID-19 patients? A retrospective observational study of a dedicated COVID-19 CPAP service. BMJ Open Respir Res 2020;7(1).

57. Panadero C, Abad-Fernandez A, Rio-Ramirez MT, Acosta Gutierrez CM, Calderon-Alcala M, Lopez-Riolobos C, et al. High-flow nasal cannula for acute respiratory distress syndrome (ARDS) due to COVID-19. Multidiscip Respir Med 2020;15(1):693.

58. Albert RK, Keniston A, Baboi L, Ayzac L, Guerin C; PROSEVA Investigators. Prone position-induced improvement in gas exchange does not predict improved survival in the acute respiratory distress syndrome. Am J Respir Crit Care Med 2014;189(4):494-496.

59. Ding L, Wang L, Ma W, He H. Efficacy and safety of early prone positioning combined with HFNC or NIV in moderate to severe ARDS: a multi-center prospective cohort study. Crit Care 2020;24(1):28.

60. Colla J, Rodos A, Seyller H, Weingart S. Fighting COVID-19 hypoxia with one hand tied behind our back: blanket prohibition of high-flow oxygen and noninvasive positive end-expiratory pressure in US hospitals. Ann Emerg Med 2020;75(6):791-792.

61. Li J, Fink JB, Ehrmann S. High-flow nasal cannula for COVID-19 patients: low risk of bio-aerosol dispersion. Eur Respir J 2020;55(5).

62. Whittle JS, Pavlov I, Sacchetti AD, Atwood C, Rosenberg MS. Respiratory support for adult patients with COVID-19. J Am Coll Emerg Physicians Open 2020.

63. Brochard L, Slutsky A, Pesenti A. Mechanical ventilation to minimize progression of lung injury in acute respiratory failure. Am J Respir Crit Care Med 2017;195(4):438-442.

64. Cruces P, Retamal J, Hurtado DE, Erranz B, Iturrieta P, Gonzalez C, et al. A physiological approach to understand the role of respiratory effort in the progression of lung injury in SARS-CoV-2 infection. Crit Care 2020;24(1):494.

65. Laffey JG, Madotto F, Bellani G, Pham T, Fan E, Brochard L, et al; ESICM Trials Group. Geo-economic variations in epidemiology, patterns of care, and outcomes in patients with acute respiratory distress syndrome: insights from the LUNG SAFE prospective cohort study. Lancet Respir Med 2017;5(8):627-638.

66. Grasselli G, Greco M, Zanella A, Albano G, Antonelli M, Bellani G, et al; COVID-19 Lombardy ICU Network. Risk factors associated with mortality among patients with COVID-19 in intensive care units in Lombardy, Italy. JAMA Intern Med 2020;180(10):1345-1355.

67. Auld SC, Caridi-Scheible M, Blum JM, Robichaux C, Kraft C, Jacob JT, et al; Emory COVID-19 Quality and Clinical Research Collaborative. ICU and ventilator mortality among critically ill adults with coronavirus disease 2019. Crit Care Med 2020;48(9):e799-e804.

68. Karagiannidis C, Mostert C, Hentschker C, Voshaar T, Malzahn J, Schillinger G, et al. Case characteristics, resource use, and outcomes of 10,021 patients with COVID-19 admitted to 920 German hospitals: an observational study. Lancet Respir Med 2020;8(9):853-862.

69. RECOVERY Collaborative Group; Horby P, Lim WS, Emberson JR, Mafham M, Bell JL, et al. Dexamethasone in hospitalized patients with COVID-19. N Engl J Med 2021;384(8):693-704.

70. Wei Dong, Yiping Gong, Juan Feng, Lang Bai, Haomiao Qing, Peng Zhou, et al. Early awake prone and lateral position in non-intubated severe and critical patients with COVID-19 in Wuhan: a respective cohort study. medRxiv 2020. 